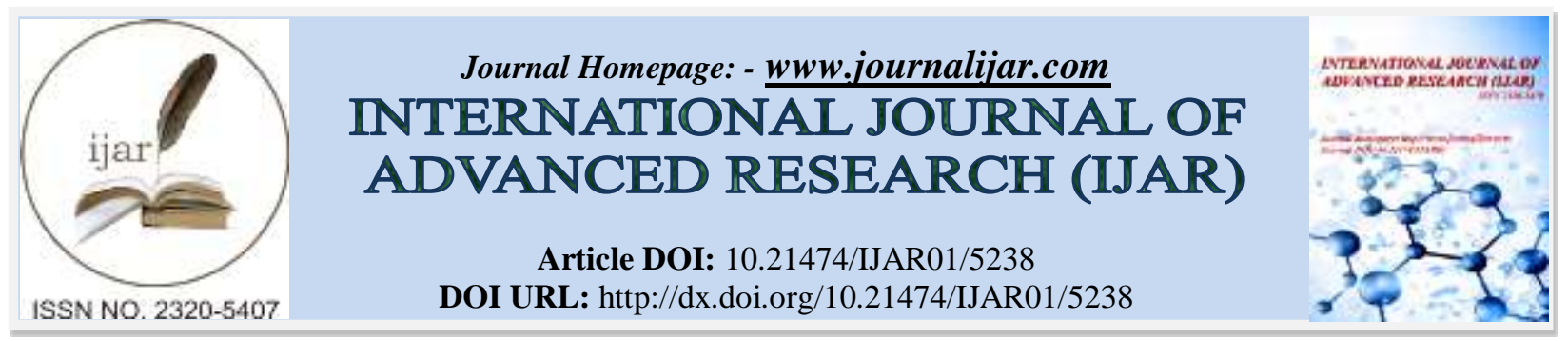

RESEARCH ARTICLE

\title{
MORPHOMETRIC CHARACTERIZATION OF THE SENEGALESE POPULATION OF COWPEA WEEVIL: Callosobruchus maculatus (Fabricius, 1775).
}

\section{Ange Kafom ${ }^{1}$, Adiouma Georges Robert Jacques Sarr ${ }^{1}$, Cheikh Abdou Khadre Mbacké Dia ${ }^{1}$, Mama Racky Ndiaye $^{1}$, Déthie Ngom ${ }^{1}$, Cheikh Thiaw ${ }^{2}$ And Mbacke Sembene ${ }^{3}$.}

1. Department of Animal Biology, Faculty of Sciences and technics, Cheikh Anta DIOP University of Dakar, PO Box 5005 Dakar, Senegal.

2. Regional Center for Studies on the Improvement, of Plant Adaptation to Drought (CERAAS), Khombole Road, PO Box 3320, Thies, Senegal.

3. BIOPASS Laboratory, IRD Bel Aire, PB. 1386, Dakar, Laboratory of Entomology and Acarology, Department of Animal Biology, Faculty of Sciences and Technology, Cheikh Anta DIOP University of Dakar.

\section{Manuscript Info}

.........................

Manuscript History

Received: 21 June 2017

Final Accepted: 23 July 2017

Published: August 2017

\section{Abstract}

African populations are confronted with food security problems. These problems can only be solved through the proper functioning of agriculture. However, to achieve food self-sufficiency, this presupposes good conservation of agricultural production for consumption as and when needed. But post-harvest losses of cereals and legumes such as cowpea are still a major problem in Senegal. Most of the losses of cowpea are due to Callosobruchus maculatus, which is the best adapted species to the life of the stocks of this legume thanks to the observed imaginal polymorphism of this species. This study has for aim the morphometric characterization of the cowpea beetle in the different agro-ecological zones of Senegal in order to verify whether the spatial distribution has an impact on the morphology of the insect. This is based on a sample of cowpea previously infected with $C$. maculatus in the different agro-ecological zones of the study framework. The results revealed the existence of morphometric groups between some agroecological zones of the study framework, in particular between the Sylvo-pastoral zone and the high Casamance in the Eastern Senegal.

Copy Right, IJAR, 2017,. All rights reserved.

\section{Introduction:-}

One of the major expectations of the African people is the resolution of the problematic of food security by the scientific community. If agriculture takes on a great importance for developing African countries, that's because besides being a major source of national income, it is vital for ensuring food security. In Senegal as in most neighbouring sahelian states, cereals and vegetables are the main food crops and the basic objective of food sufficiency planned in several countries (Seck 1989). The increasing of agricultural production becomes an emergency. Then, to face the demographic growth; it would be imperial to manage both edaphic, climatic and biotic factors which influence the parasitic pressure upon seeds and their harvest but also on the population of insects on the fields as well as in stocks (Ngamo et Hance, 2007; Kayombo et al., 2015). Indeed, if food self-sufficiency means producing enough, it pretends a good conservation of that production as need goes on. But the post-harvest losses of cereals and legumes are still a big problem in Senegal and in West Africa. According to a report from FAO (2011), 
it estimates around 4 billion dollars/year the post-harvest losses in the sub-saharian region. Those losses vary from one country to another: they are weak in industrialised countries and very high in saharian regions where they can reach 30\% (Ngamo et Hance, 2007). Among the causes of those losses, harmful insects are 44\% responsible (Sezonlin, 2006), the main pest insects of cereals and legumes are of two categories: those attacking harvests from the field like the Carryedon seratus (Olivier) on groundnuts and Callosobruchus maculatus (F.) on black eyed peas and those exclusively enfeoffed to stocks such as Corcyra cephalonica (Stainton) and T. castaneum (Herbst) (Gueye et al., 2011). According to Ilboudo (2009), the main loss of black-eyed peas is due to Callosobruchus maculatus which are the species more likely to live in the stocks of that legume thanks to imaginal polymorphisms found with that species. Here lays the importance of morphogenetic characterization of black eyed peas in order to elaborate a good strategy to fight against this pest. In so doing, a morphometric study on $C$. maculatus will be undertaken to check if the spatial distribution will have an impact on its morphology, in other words are the Senegalese groups of C. maculatus morphologically different?

\section{Tools And Methods:-}

\section{Sampling:-}

The sampling was carried out in 9 localities of Senegal where black eyed peas are produced in large quantities, taking into account the infestation and the geographical position. The 9 localities sampled are respectively:

* Bambey: $14^{\circ} 45^{\prime}$ North and 16³0' West

( North side of the groundnut basin "NBA");

* Nioro $13^{\circ} 45^{\prime}$ North and $15^{\circ} 48^{\prime}$ ' West

(North groundnut basin "NBA");

* Tamba: 13॰46’14" North and 1340’2

West (High Casamance in the Eastern Senegal « HCSO») ;

* Kébémer: $15^{\circ} 15^{\prime}$ North and $16^{\circ} 15^{\prime}$ West

(Sylvo-Pastoral area « SP »);

* Linguere: $15^{\circ} 24^{\prime}$ North et $15^{\circ} 07^{\prime}$ West

(Sylvo- Pastoral area « SP »)

* Diofior: $14^{\circ} 10^{\prime} 60^{\prime \prime}$ North et $16^{\circ} 40$ West

(South groundnut basin « SBA ») ;

* Sandiara: $14^{\circ} 42^{\prime}$ North and

$16^{\circ} 25^{\prime} 60^{\prime}$ 'West (Southern part of groundnut bassin «SBA »);

* Fouta: $16^{\circ} 18^{\prime}$ North and $14^{\circ} 48^{\prime}$ West

(the Senegal River Valley «VFS ») ;

* Ourossogui: $15^{\circ} 36^{\prime}$ North and

$13^{\circ} 19^{\prime}$ West (the Senegal River valley « VFS »).

Black eyed peas' seed samples are returned to the insectarium and transferred to jars to increase the population sampled by a second generation. The insects that emerged from the jars were stored in $96^{\circ}$ alcohol so that they would not be degraded. Each individual in a sample is paired with a code, using the first letter of the gender name in uppercase followed by the first two letters of the original place.(the first letter in upper case and the second letter in lower case), and finally in an order number. (Table 1).

Table 1:- Summary table of the sampling.

\begin{tabular}{|l|l|l|l|}
\hline Localities & Agro-écologic areas & Number of individuals & Sample code \\
\hline Bambey & \multirow{2}{*}{ NBA } & 15 & $\mathrm{CmB}$ \\
\hline Nioro & & 15 & $\mathrm{CmN}$ \\
\hline Tamba & HCSO & 15 & $\mathrm{CmT}$ \\
\hline Kebemer & \multirow{2}{*}{ SP } & 15 & $\mathrm{CmK}$ \\
\hline Linguere & & 15 & $\mathrm{CmL}$ \\
\hline Diofior & \multirow{2}{*}{ SBA } & 15 & $\mathrm{CmD}$ \\
\hline Sandiara & & 15 & $\mathrm{CmS}$ \\
\hline Fouta & \multirow{2}{*}{ VFS } & 15 & $\mathrm{CmFo}$ \\
\hline Ourossogui & & 15 & $\mathrm{CmO}$ \\
\hline
\end{tabular}




\section{Morphometric study:-}

The biological material consists of Callosobruchus maculatus males that were reared in high temperature jars after sampling of black eyed peas' seeds in different localities in Senegal. Only the male insects are used for the morphometric study, lest the female insects spoil the measurements because they can be gravid at the time of their conservation, and thus cause a change in morphology and their pygidium becomes much greater due to the eggs which are there. This could change the data on the last sternite.

The insect is taken out of the alcohol by a forceps and put in distilled water to be washed. Then it is transferred onto paper in order to be dried (the paper will aspire the water in which was soaked the insect). The insect is then placed on a binocular magnifying glass where it is fixed using needles on the graph paper placed in the field of vision of the lit magnifier. The magnifying glass is adjusted with adequate enlargements so that the insect is clearly visible for dissection. The insect is dissected using pliers and razor blade, first separating its three parts namely the head, thorax and abdomen. Then each part is subsequently dissected in turn by separating the various articles which it is made of. The items are then measured using the graph paper. In total, 15 variables are measured for the purpose of our study (table 2).

Table 2:- Measured Variables

\begin{tabular}{|l|l|l|}
\hline Measured Variables & Thorax & Abdomen \\
\hline Head & $\begin{array}{l}\text { Length of the pronotum to the center } \\
\text { Lengh of the antenna (Lan) }\end{array}$ & $\begin{array}{l}\text { Maximum length of the first } \\
\text { abdominal sternitis (Los) }\end{array}$ \\
$\begin{array}{l}\text { Minimum distance between eyes } \\
\text { ventrally (Dvy) } \\
\text { Width of the pronotum (Lap) } \\
\text { The biggest dimension of the fleuer } \\
\text { Minimum distance between eyes } \\
\text { dorsally (Lmf) }\end{array}$ & $\begin{array}{l}\text { Maximum width of first abdominal } \\
\text { sternitis (Las) } \\
\text { The biggest dimension of the tibia } \\
\text { Maximum width of the head (Lmt) } \\
\text { Number of teeth in the femur 3 (den) } \\
\text { Maximum length of the elytra } \\
\text { (Lds) } \\
\text { (Loe) laxth of last sternitis } \\
\text { Maximum lengh of the elytra (Lae) }\end{array}$ & $\begin{array}{l}\text { Maximum width of last sternitis } \\
\text { (lds) }\end{array}$ \\
\hline
\end{tabular}

\section{Statistic analysis:-}

Gross measurement:-

A discriminating factorial analysis of populations with gross measurements of variables regarding sampled agroecologic areas has been carried out with software $\mathrm{R}$ version 3.2.3 (Bloomfield, 2014) in order to extract the contribution of each variable according to its Gross measurements in order to see the most discriminating and to discriminate morphometric groups according to the agro-ecological areas.

\section{Transformed measurements :- * Size effect}

According to Santos (2015) the size effect is manifested by a correlating circle which gathers all the variables in a single plane for a given axis. This is a very undesirable effect, which metric studies seek to free themselves from. The principle of elimination is then to bring all the individuals to the same size, in order to observe on the PCA only differences of shape.

\section{* Data transformation}

The elimination of the size effect that affects almost all biometric studies was carried out using the following approach proposed by Santos (2015):

- Data log transformation: The initial data

table consists of the variables $\mathrm{X} 1, \mathrm{X} 2, \ldots, \mathrm{Xp}$, thereafter a new data table consisting of $\log (\mathrm{X} 1), \log (\mathrm{X} 2), \ldots, \log$ (Xp) has been created.

- For each individual, the overall average

of variables transformed log has been calculated. This average score is a good idea of the "size" for this individual.

- Finally, for each individual, the mean

size obtained with the transformed Logs was subtracted from each of these raw measurements. 
The size effect is thus eliminated and only the difference in shape will be observed on the ACP. The reduction in the weight of this factor (Size) results in a reduction of the global discrimination between the populations and the reduction of the distance between the centers of gravity of the populations. This transformation was made through Excel version 2011.

\section{Discriminatory Factorial analysis:-}

A discriminatory factorial analysis (AFD) of the populations with the transformed data of the variables according to the localities and the sampled host plants was carried out with software R version 3.2.3 (Bloomfield, 2014). The purpose of this analysis is to extract the contribution of each variable after elimination of the size effect in order to see the differences in shape between the population groups revealed by the discriminating power of each of the variables.

\section{Factorial Analysis of Correspondence (FNC):-}

The factorial correspondence analysis (AFC) is performed to visualize the relationships between individuals of different populations from the transformed data and to test for possible metric similarities between these populations. It is a multivariate analysis method that considers transformed measurements of all populations as variables (Hoda and Marsan, 2012). For this purpose, a graphical representation is produced from the transformed data which are adapted using the Genetix version 4.05.2 program (Belkhir et al., 2004) to estimate the distribution of morphological diversity at all levels (individuals, -populations and total population).

\section{Assignment test:-}

Assigning individuals is a method of determining the likelihood of an individual belonging to his / her source population (origin). The population assignment approach of Cornuet et al. (1999), which calculates for each individual its probability of belonging to each sampled population was used. In principle, the exclusion-simulation approach proposed by Cornuet et al 1999 calculates the probability according to which an individual belongs to a population simulating 10000 individuals. The threshold of the p-value is fixed according to a certain exclusion required (generally between 0.05 and 0.001 ). An individual is considered to be correctly assigned to a population when it is excluded from all others with a highly significant probability $(p<0.001)$, except the one from which it originates.

The test of the assignment of individuals in their populations a posteriori relative to their population of origin a priori is realized by the software GeneClass version 2.0 (Piry et al., 2004) in order to determine the probability of belonging of an individual To its source population. The threshold for assigning scores was set at $5 \%$.

\section{Hierarchical ascending classification:-}

It represents a method of tree construction that often requires a delicate construction and is difficult to generalize if the learning data are poorly representative of reality. Automatic classification methods that do not require learning are of great interest when the data are completely unknown.

In this way, it is possible to extrapolate from classes which are not obvious a priori. Therefore, HAA consists in grouping individuals according to their resemblance or dissimilarity. The ascending hierarchical classification is carried out in Excel version 2011.

\section{Results and discussions:-}

\section{Raw data:-}

\section{Contribution of variables with raw measurements:-}

The analysis concern Lan, Dvy, Lmt, Lop, Lap, Lf3, Lt3, Loe, Lae, Los, Las, Lds, lds because 2 variables (Lmf and den) have values that remain constant for all individuals. As a result, they are discarded from the analyzes.

The discriminatory factorial analysis explains $48.41 \%$ of the total morphometric variability on two dimensions. With a percentage of inertia of $(35.73 \%)$, the factorial axis of dimension 1 (F1) is constructed by values such as: Loe (F1=16,59), Lap (F1=15,05), Lt3 (F1=14,18), Lae (F1=12,54), Lop (F1=11,16), Lmt (F1=10,91), Lf3(F1=8,37) ; whereas variables such as Los $(\mathrm{F} 1=4,47)$, dvy $(\mathrm{F} 1=2,68)$, lds $(\mathrm{F} 1=1,79)$, Las $(\mathrm{F} 1=1,24), L d s \quad(\mathrm{~F} 1=0,96$, weakly contribute in the construction of the first axis.

The second factorial axis with a percentage of inertia of $12.68 \%$ is represented with a strong contribution of variables such as: $\operatorname{lds}(\mathrm{F} 2=41,52)$, Las $(\mathrm{F} 2=40,66), \quad L f 3(\mathrm{~F} 2=5,32)$, whereas the other variables such as $L d s$ 
(F2=4,35), Los (F2=4,13), Lmt (F2=2,19), dvy (F2=0,62), Lap (F2=0,61), Loe ( $\mathrm{F} 2=0,39)$, Lt3(F2=0,13), Lop $(\mathrm{F} 2=0,03)$, Lae $(\mathrm{F} 2=0,0005)$ weakly contribute in the construction of the axis (fig 1). A globally positive correlation for the variables, along the factorial axis of dimension 1, seems to suggest an influence of the data by the "size effect".

Variables factor map (PCA)

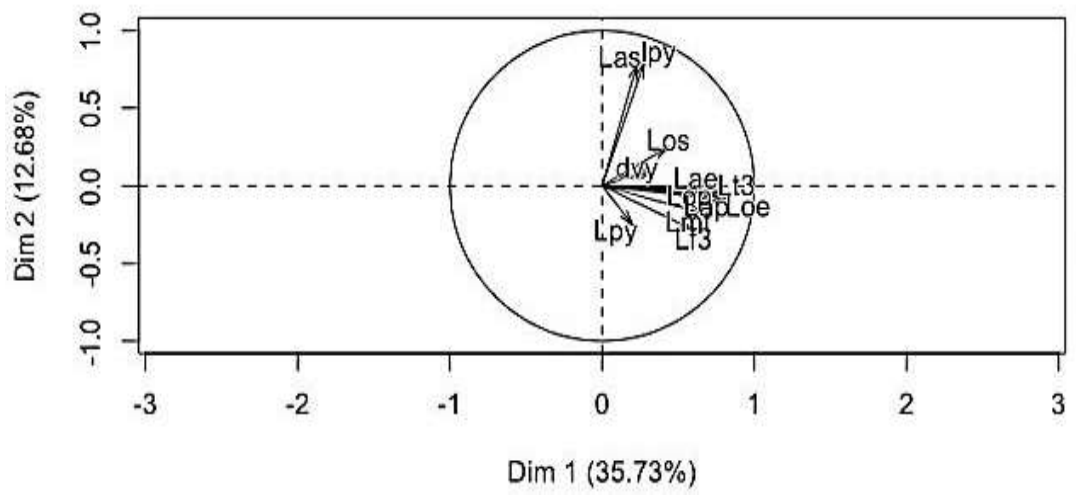

Figure 1:- Contribution of discriminatory variables to the two factorial axis 1 and 2

\section{Discrimination of populations according to raw measurements:-}

The best quality of representation is given by the plan 1-2 (factorial axis 1 and 2) with $48.4 \%$ of the total discriminating power and does not give a significant discrimination between the populations. The first axis does not clearly discriminate populations at first glance. However, focusing on the barycenter of the ecotypes, the populations of the Senegal river valley (VFS) and the High Casamance in the Eastern Senegal (HCSO) seem to be slightly discriminated against those in the sylvo pastoral zone (SP) and the northern groundnut basin (NBA) with significant introgressions and as an intermediate population between the two groups mentioned, that of the southern groundnut basin (SBA).

The second axis weakly discriminates two groups: the populations of the Senegal river valley (VFS) and the high Casamance in the Eastern Senegal (HCSO) of the populations of the sylvo pastoral zone (SP), the northern groundnut basin (NBA), the southern basin groundnut (SBA).

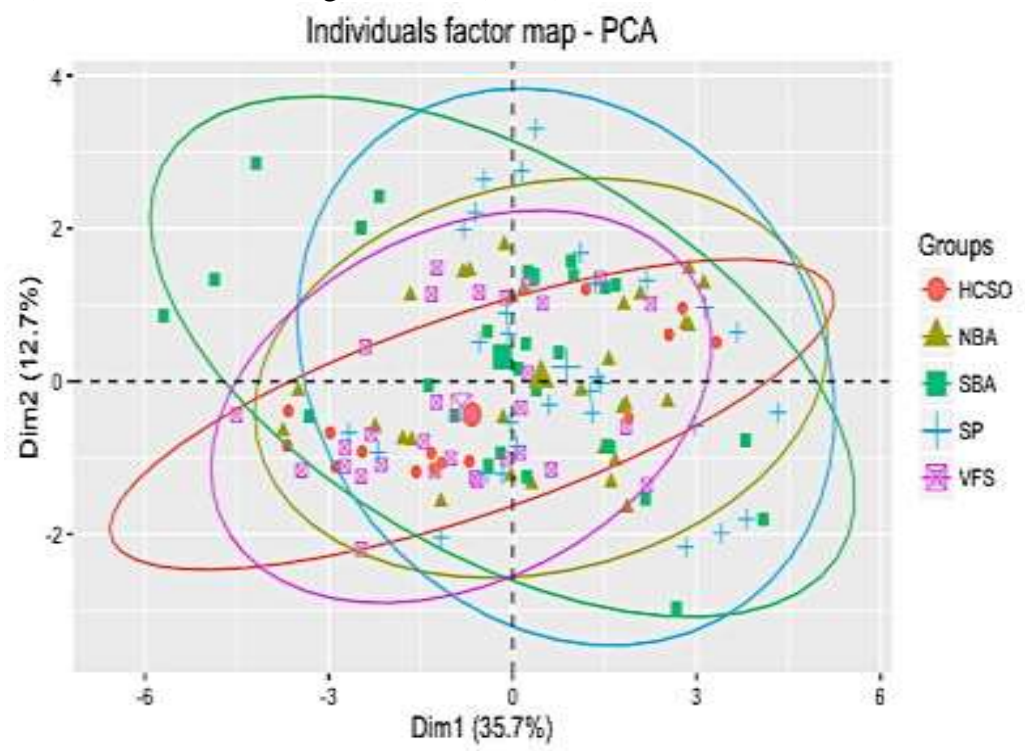

Figure 2:- Representation in the main AFD plan of the populations of Callosobruchus maculatus according to the agro-ecolgic zones. 


\section{Identification of discriminating variables of raw data:-}

Variables allowing discrimination of agro-ecological areas are determined by the Tukey Kramer test. This test consists in comparing the average of each variable between the ecotypes in order to determine the variables that make it possible to discriminate the populations. Depending on the two factorial axes, the low discrimination between HCSO and other agro-ecological areas is due to the maximum length of the last sternite. In addition to the maximum length of the last sternite (Lds), the largest dimension of the tibia 3 (Lt3) allows the low discrimination of the HCSO and the NBA, Minimum distance between the ventral eyes (Dvy) and the length of the pronotum in the center (Lop) allow the low discrimination of the HCSO and the SP area. The largest dimension of the tibia 3 (Lt 3) is responsible for the low differentiation between the NBA and the other agro-ecological zones. In addition to the latter (Lt3), the length of the antenna (Lan) discriminates the NBA and SBA; The length of the pronotum at the center (Lop) slightly differentiates NBA and SP; The length of the antenna (Lan), the maximum length of the elytra (Loe) and the maximum length of the last sternite (Lds) discriminate NBA and VFS.

Table 3:- Average size of all individuals for each agro-ecological zone according to the variables measured.

\begin{tabular}{|c|c|c|c|c|c|}
\hline $\begin{array}{l}\text { Agro-ecological zones } \\
\text { Variables }\end{array}$ & HCSO & NBA & SBA & SP & VFS \\
\hline dvy & $0,280,04^{\mathrm{a}}$ & $0,30 \quad 0,00^{a b}$ & $0,30 \quad 0,02^{a b}$ & $0,300,03^{b}$ & $0,28 \quad 0,03^{a b}$ \\
\hline Lae & $0,810,09^{a}$ & $0,890,88^{a}$ & $0,850,11^{\mathrm{a}}$ & $0,870,08^{a}$ & $0,83 \quad 0,16^{a}$ \\
\hline Lan & $1,810,15^{\mathrm{ab}}$ & $1,870,17^{b}$ & $1,720,20^{a}$ & $1,770,22^{\mathrm{ab}}$ & $1,710,21^{a}$ \\
\hline Lap & $1,040,07^{\mathrm{ab}}$ & $1,05 \quad 0,07^{\mathrm{ab}}$ & $1,040,11^{\mathrm{a}}$ & $1,110,08^{b}$ & $1,030,07^{\mathrm{a}}$ \\
\hline Las & $0.130 .04^{\mathrm{a}}$ & $0.140 .04^{\mathrm{a}}$ & $0.140 .05^{a}$ & $0.140 .05^{\mathrm{a}}$ & $0.130 .04^{a}$ \\
\hline Lf3 & $0.980 .11^{\mathrm{a}}$ & $1.010 .07^{\mathrm{a}}$ & $0.990 .09^{a}$ & $1.020 .08^{\mathrm{a}}$ & $1.000 .06^{\mathrm{a}}$ \\
\hline Lmt & $0.720 .05^{\mathrm{ab}}$ & $0.760 .06^{\mathrm{ab}}$ & $0.710 .10^{\mathrm{a}}$ & $0.780 .06^{b}$ & $0.720 .06^{\mathrm{a}}$ \\
\hline Loe & $1.730 .14^{\mathrm{ab}}$ & $1.800 .17^{b}$ & $1.770 .15^{\mathrm{ab}}$ & $1.760 .13^{\mathrm{ab}}$ & $1.680 .13^{a}$ \\
\hline Lop & $0.760 .06^{\mathrm{a}}$ & $0.760 .08^{a}$ & $0.810 .11^{\mathrm{a}}$ & $0.870 .07^{b}$ & $0.800 .06^{\mathrm{a}}$ \\
\hline Los & $1.390 .16^{\mathrm{ab}}$ & $1.400 .19^{\mathrm{ab}}$ & $1.460 .13^{b}$ & $1.370 .13^{\mathrm{ab}}$ & $1.300 .11^{\mathrm{a}}$ \\
\hline Ids & $0.220 .04^{\mathrm{a}}$ & $0.250 .05^{\mathrm{a}}$ & $0.250 .05^{\mathrm{a}}$ & $0.270 .09^{\mathrm{a}}$ & $0.230 .05^{a}$ \\
\hline Lds & $1.120 .08^{\mathrm{c}}$ & $1.000 .01^{\mathrm{a}}$ & $1.030 .07^{\mathrm{ab}}$ & $1.010 .13^{\mathrm{ab}}$ & $1.070 .05^{b c}$ \\
\hline Lt3 & $0.810 .10^{\mathrm{ab}}$ & $0.910 .07^{\mathrm{c}}$ & $0.820 .09^{\mathrm{ab}}$ & $0.850 .08^{b}$ & $0.850 .08^{a}$ \\
\hline
\end{tabular}

Transformed data:-

\section{Contribution of variables:-}

In contrast to the raw data, the factor analysis with the transformed data shows a reduction in the percentage of inertia of $6.13 \%$ for the first dimension (factorial axis 1) following a decrease in the discriminating power of most taxpayer variables among which: Lap (F1=12,65), Lt3 (F1=12,62), Lae ( $\mathrm{F} 1=10,22)$, Lmt ( $\mathrm{F} 1=7,96)$, Lf3 (F1=7,69), Lop $(\mathrm{F} 1=6,97)$ and mainly, a fairly significant contribution of two variables, the power of which discriminates a Las gain $(\mathrm{F} 1=13.89)$, lds $(\mathrm{F} 1=6.44)$, while contributing weakly with the raw data. The second factor axis with an almost imperceptible decrease $(0.11 \%)$, shows an inverse situation compared to the results with the raw data, with an increase in the discriminating power of almost all the variables and a significant contribution of certain variables as: $d v y(\mathrm{~F} 2=25,00), \operatorname{Los}(\mathrm{F} 2=15,08), \operatorname{Lpy}(\mathrm{F} 2=8,71), \operatorname{Lmt}(\mathrm{F} 2=7,02), \operatorname{Lae}(\mathrm{F} 2=6,58)$. Whereas the length of the femur $3 \mathrm{Lf} 3(\mathrm{~F} 2=5.23)$ and especially the maximum width of the first abdominal sternite Las $(\mathrm{F} 2=3.76)$ show a decrease in discriminating power and a small contribution to the second dimension (axis 2). The best quality representation is always obtained with the plane formed by the axis 1 and 2 with a total inertia percentage of $42.17 \%$. 


\section{Variables factor map (PCA)}

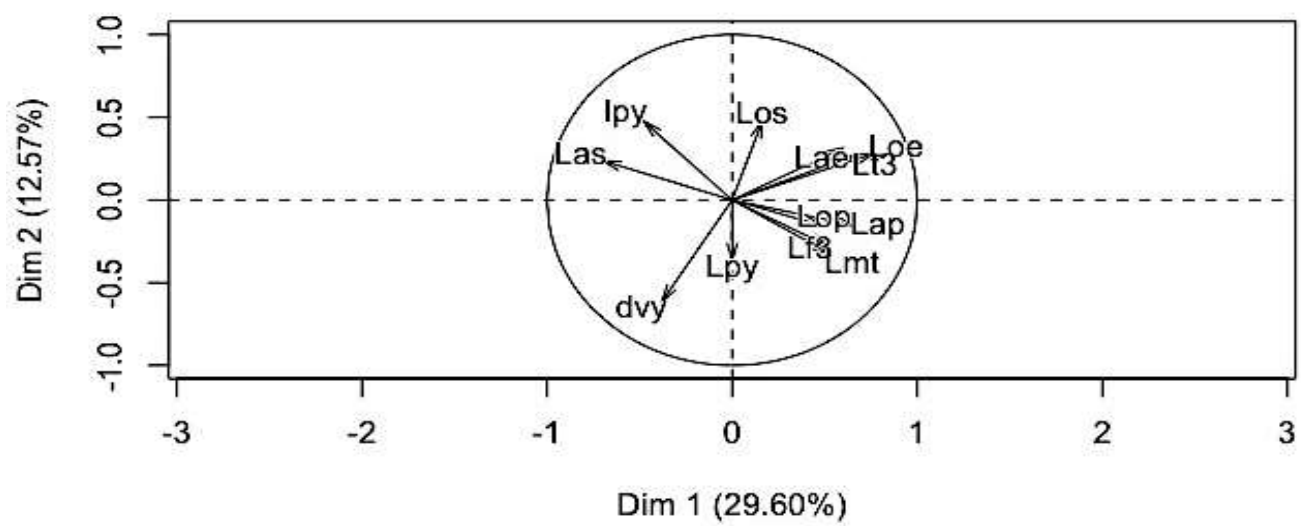

Figure 3:- Contribution of discriminant variables to axes 1 and 2 with transformed data.

\section{Discrimination of populations with transformed measurements of variables:-}

With the transformed measurements, according to the two factorial axes, the agro-ecological zones shows a low discrimination. Thus, with a reduction in the percentage of inertia, the first dimension allows a slight discrimination of the populations of the High Casamance in the Eastern Senegal (HCSO), the Senegal River valley (VFS), the southern groundnut basin (SBA), the northern groundnut basin (NBA) and the sylvo pastoral zone (SP). Contrariwise, the second dimension reveals discrimination on the one hand between the populations of the southern groundnut basin (SBA) of those of the high Casamance in the Eastern Senegal (HCSO) and the Senegal River valley (VFS), on the other hand between population of the sylvo pastoral zone (SP) and that of the northern groundnut basin (NBA).

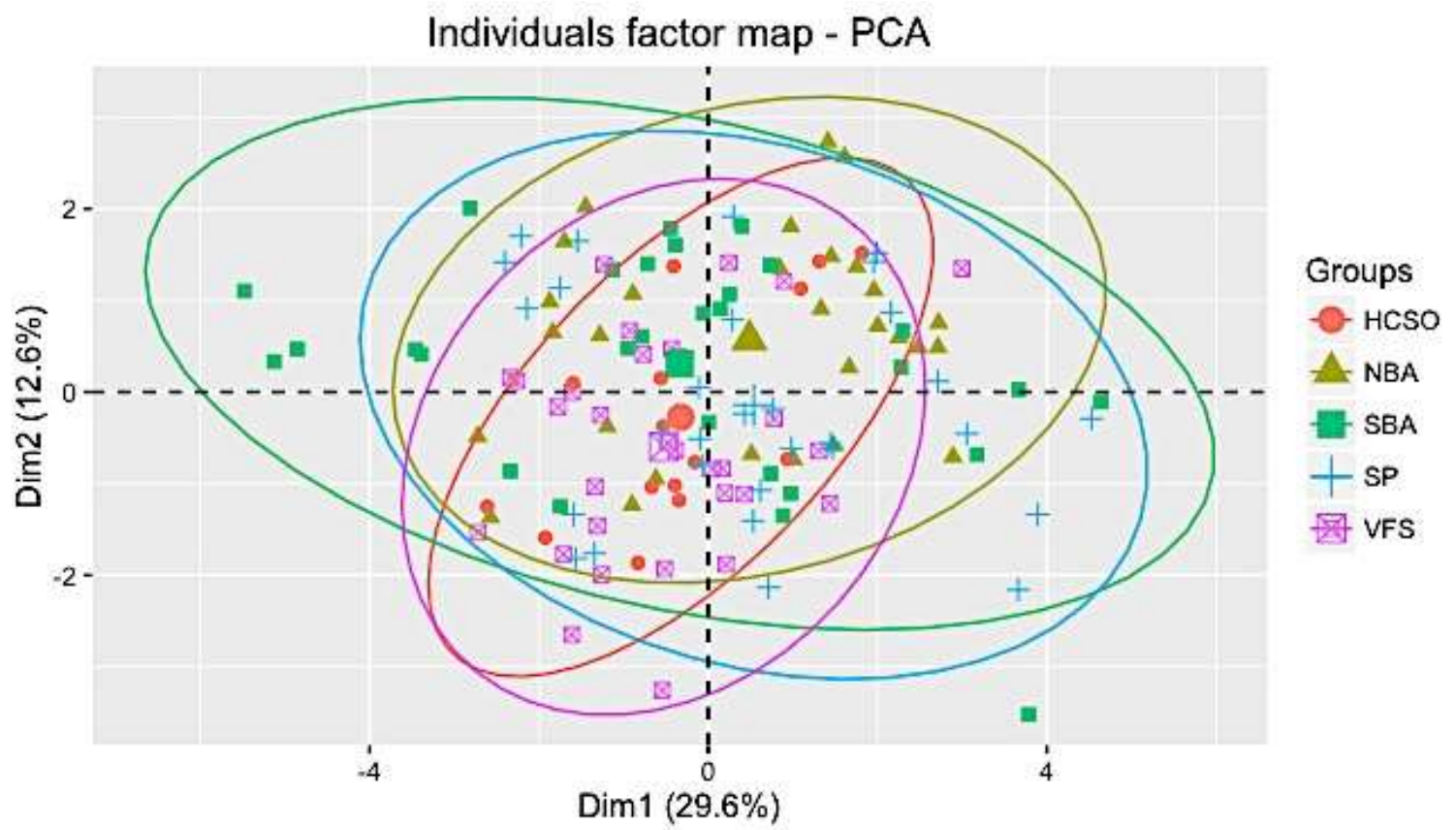

Figure 4:- Ecotype discrimination according to transformed data. 


\section{Identification of variables enabling discrimination of populations:-}

Depending on the first factorial axis, the low discrimination between HCSO and NBA is due to the maximum length of the last sternite (Lds). The maximum length of the last sternite (Lds) and the length of the pronotum at the center (Lop) discriminates HCSO and SP. As for the VFS and the SP area, it is the width of the pronotum (Lap) and the maximum width of the first abdominal sternite that differentiate them. Between the VFS and the NBA, it is the length of the elytra (Loe), the length of the pronotum at the center (Lop) and the maximum length of the last sternite (Lds) that allow low discrimination. The low discrimination between the SBA and the SP area is due to the width of the pronotum (Lap), the maximum width of the head (Lmt) and the length of the pronotum (Lop). The length of the antenna (Lan) differentiates the SBA from the NBA.

Depending on the second factorial axis, the differentiation between SBA and HCSO is due to the maximum length of the last abdominal sternite (Lds). This same variable (Lds) and the maximum length of the first abdominal sternite (Los) slightly discriminate SBA and VFS. Variables such as the width of the pronotum and the length of the pronotum at the center (Lop) discriminate the SP area of NBA.

Table 4:- Average size of all individuals for each agro-ecological area according to the measured variables.

\begin{tabular}{|c|c|c|c|c|c|}
\hline & \multicolumn{5}{|c|}{ AGROECOLOGIcal area } \\
\hline variables & HCSO & NBA & SBA & SP & VFS \\
\hline dvy & $0.420 .04^{\mathrm{a}}$ & $0.430 .03^{\mathrm{a}}$ & $0.430 .03^{\mathrm{a}}$ & $0.430 .04^{\mathrm{a}}$ & $0.430 .03^{\mathrm{a}}$ \\
\hline Lae & $0.960 .06^{\mathrm{a}}$ & $1.020 .06^{\mathrm{a}}$ & $0.980 .10^{\mathrm{a}}$ & $0.990 .07^{\mathrm{a}}$ & $0.980 .15^{\mathrm{a}}$ \\
\hline Lan & $1.960 .15^{\mathrm{ab}}$ & $2.000 .17^{b}$ & $1.820 .22^{\mathrm{a}}$ & $1.890 .23^{\mathrm{ab}}$ & $1.860 .22^{\mathrm{ab}}$ \\
\hline Lap & $1.180 .05^{\mathrm{ab}}$ & $1.180 .06^{\mathrm{a}}$ & $1.180 .10^{\mathrm{a}}$ & $1.230 .07^{\mathrm{b}}$ & $1.180 .05^{\mathrm{a}}$ \\
\hline Las & $0.280 .02^{a}$ & $0.270 .03^{\mathrm{a}}$ & $0.280 .05^{\mathrm{a}}$ & $0.270 .04^{\mathrm{a}}$ & $0.280 .04^{\mathrm{a}}$ \\
\hline Lf3 & $1.130 .08^{\mathrm{a}}$ & $1.140 .06^{\mathrm{a}}$ & $1.150 .20^{\mathrm{a}}$ & $1.140 .07^{\mathrm{a}}$ & $1.150 .06^{\mathrm{a}}$ \\
\hline Lmt & $0.870 .04^{a b}$ & $0.880 .06^{\mathrm{ab}}$ & $0.850 .08^{a}$ & $0.900 .06^{b}$ & $0.870 .06^{\mathrm{ab}}$ \\
\hline Loe & $1.880 .11^{\mathrm{ab}}$ & $1.930 .16^{b}$ & $1.900 .14^{\mathrm{ab}}$ & $1.880 .12^{\mathrm{ab}}$ & $1.830 .11^{\mathrm{a}}$ \\
\hline Lop & $0.910 .05^{\mathrm{ab}}$ & $0.890 .06^{\mathrm{a}}$ & $0.930 .09^{\mathrm{ab}}$ & $0.990 .06^{\mathrm{c}}$ & $0.950 .05^{b c}$ \\
\hline Los & $1.540 .13^{\mathrm{ab}}$ & $1.530 .19^{\mathrm{ab}}$ & $1.580 .13^{b}$ & $1.490 .12^{\mathrm{ab}}$ & $1.450 .09^{\mathrm{a}}$ \\
\hline lds & $0.370 .02^{\mathrm{a}}$ & $0.380 .04^{\mathrm{a}}$ & $0.390 .05^{\mathrm{a}}$ & $0.390 .08^{\mathrm{a}}$ & $0.380 .04^{\mathrm{a}}$ \\
\hline Lds & $1.270 .06^{b}$ & $1.130 .03^{\mathrm{a}}$ & $1.150 .06^{\mathrm{a}}$ & $1.130 .13^{\mathrm{a}}$ & $1.220 .05^{b}$ \\
\hline Lt3 & $0.960 .07^{\mathrm{a}}$ & $1.040 .06^{b}$ & $0.950 .08^{a}$ & $0.970 .07^{\mathrm{a}}$ & $0.930 .06^{\mathrm{a}}$ \\
\hline
\end{tabular}

Factorial analysis of correspondence (AFC):-

The discriminating factorial analysis reveals that the first five factorial axes explain all the morphometric variability of this beetle. However, the plan formed by the first three axes best explains the discriminatory situation of agroecological zones with an inertia of $79.63 \%$. The first factorial axis with an inertia of $26.49 \%$, discriminates the group formed mainly by the individuals of the High Casamance in the Eastern Senegal (HCSO) and some individuals of the Northern Groundnut Basin (NBA) and the Sylvo pastoral zone (SP) of the other groups. The second factorial axis with an inertia of $26.7 \%$, discriminates the other groups from that containing almost all the individuals of the Southern Groundnut Basin (SBA). The third factorial axis with a $24.43 \%$ inertia allows the discrimination of the group which contains a large part of the individuals of the SBA, the group formed mainly by the individuals of the SP and the NBA with introgressions of some individuals of the others ecotypes. 


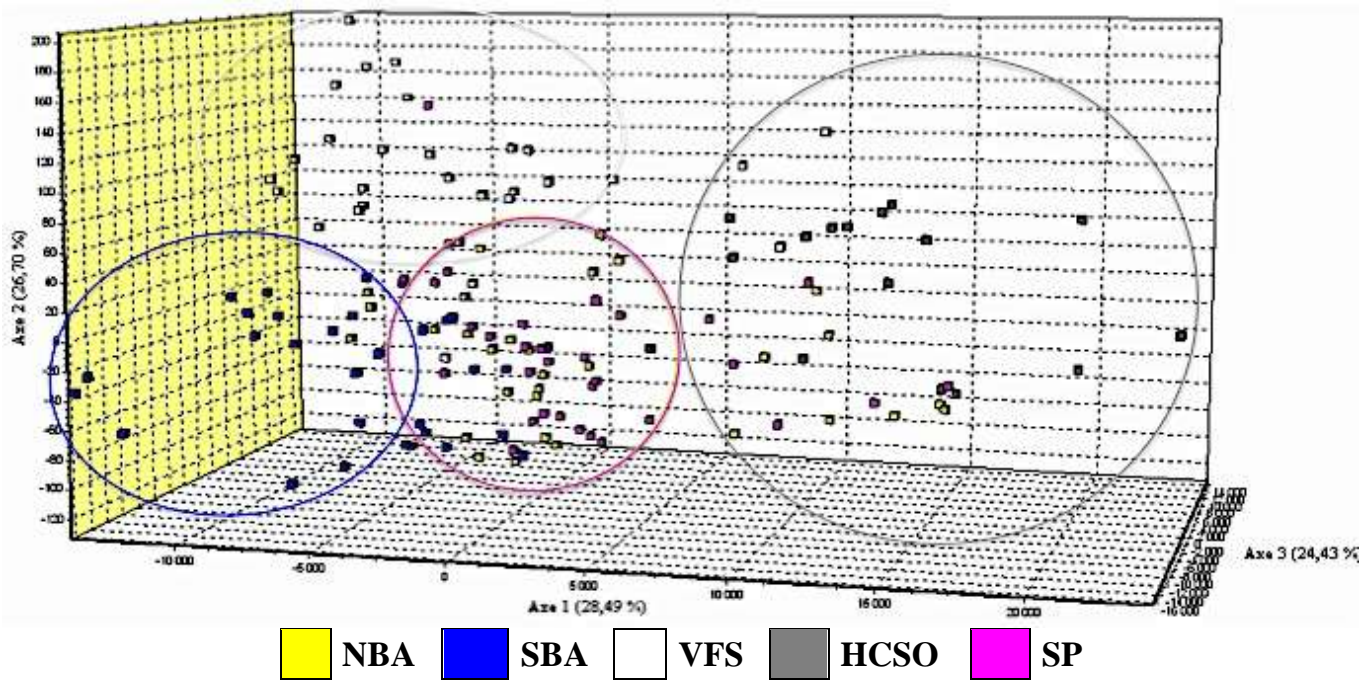

Figure 5:- simulation of morphometric variability between agro-ecological zones according to the first three axes of the AFC.

\section{Assignment test:-}

According to the assignment test, all agro-ecological zones have less than half their individuals correctly assigned, while the largest number of individuals are found to be incorrectly classified in other populations. The VFS population ranks as the highest ranked population with $46.7 \%$ of its appropriately assigned individuals, and nearly half of the individuals poorly classified in the NBA ecotypes $(6.7 \%)$, the $\operatorname{HCSO}(13,3 \%)$ and especially in the SP area $(23.3 \%)$ and the SBA (33.3\%). Just under half of the SBA's $(46.7 \%)$ are assigned to VFS.

However, the test reveals that the HCSO population has the highest number of poorly assigned individuals. In fact, only $6.7 \%$ of the individuals in this population are maintained in their pre-defined population, while more than $90 \%$ of the individuals sees itself reassigned to other areas: $26.7 \%$ in the NBA as well as the VFS, And $20 \%$ at the SBA and also at the SP zone. The HCSO receives no share of poorly assigned individuals from the SBA.

The SBA appears to be the most heterogeneous because it receives the largest share of poorly assigned individuals (116.6), and sees $30 \%$ of its individuals correctly classified, while the majority is unequally assigned in other agroecological zones: $20 \%$ In the NBA, 26.7\% in the SP zone and $46.7 \%$ in the VFS.

The populations of NBA and SP also appear to be scattered with respectively $26.7 \%$ and $20 \%$ of their individuals who are correctly assigned and the rest of the individuals distributed in the other agro-ecological zones apparently in almost similar proportions (30 and $33.3 \%$ at the SBA, $13.3 \%$ at the VFS, $16.7 \%$ at the HCSO).

Table 5:- Percentage of individuals correctly or incorrectly assigned

Percentage of individuals

\begin{tabular}{|l|l|l|l|l|l|l|l|}
\hline \multicolumn{2}{|l|}{ Incorrectly assigned to P $<0,001$} & \multicolumn{2}{l|}{ Correctly assigned } \\
\hline From /To & NBA & SBA & VFS & HCSO & SP & P $<0,05$ & P $<0,001$ \\
\hline NBA & & $30 \%$ & $13,3 \%$ & $16,7 \%$ & $13,3 \%$ & $23,33 \%$ & $26,7 \%$ \\
\hline SBA & $20 \%$ & & $46,7 \%$ & & $26,7 \%$ & $30 \%$ & $30 \%$ \\
\hline VFS & $6,7 \%$ & $33,3 \%$ & & $13,3 \%$ & $23,3 \%$ & $30 \%$ & $46,7 \%$ \\
\hline HCSO & $26,7 \%$ & $20 \%$ & $26,7 \%$ & & $20 \%$ & $6,7 \%$ & $6,7 \%$ \\
\hline SP & $16,7 \%$ & $33,3 \%$ & $13,3 \%$ & $16,7 \%$ & & $23,33 \%$ & $20 \%$ \\
\hline TOTAL & & & & & & $24,4 \%$ & $23 \%$ \\
\hline
\end{tabular}

Hierarchical ascending classification (HAC):-

The hierarchical ascending classification brings out several morphometric groups on the basis of similarities, starting from the variables. The truncation distinguishes two classes:

- Class 1 : containing only one individual 
of the SBA

- Class 2 : split into 2 subclasses

$>$ Subclass 1 with 1 individual (Cmw9);

$>$ Subclass 2 subdivided into 2 groups :

- Group 2-1 grouping individuals SBA

and SP;

- Group 2-2 itself split into 2 subgroups :

* Subgroup 2-2-1 : containing the

majority of SBA and SP individuals including some VFS individuals,

* Subgroup 2-2-2 grouping 2 sets: set 1

with only 2 individuals (CmN14, CmS5) and the more heterogeneous set 2 being divided into 2 subsets;

$\checkmark$ Subset 1: the majority of individuals

are from NBA and HCSO with a smaller portion of SP, VFS and SBA individuals.

$\checkmark$ Subset 2 exclusively with SP individuals

(Linguere).

The classification shows that the HCSO population is closer to that of the NBA. While the population of the SBA seems closer to that of SP and a little less than that of the NBA.

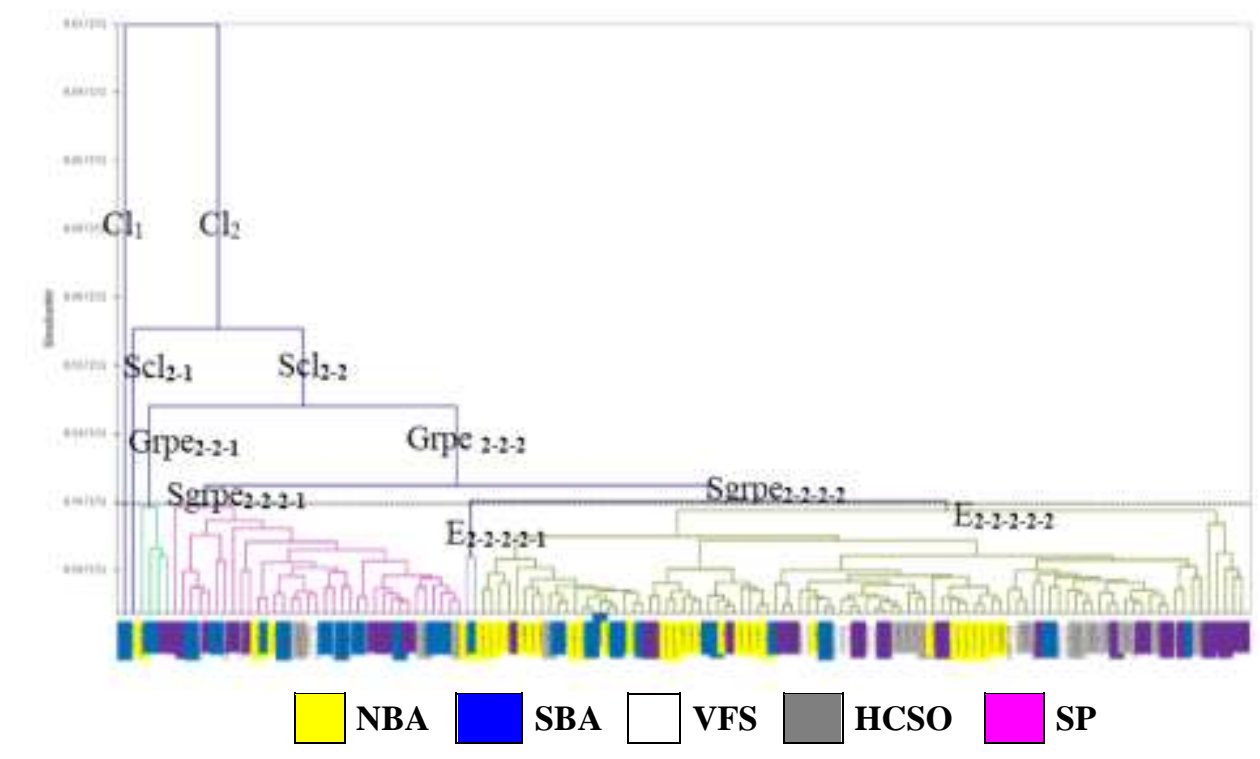

Figure 6:- dendrogram of hierarchical ascending classification as a function of similarity: Cl1: class1; Cl2: class 2; Scl2-1: subclass 1 of class 2; Scl2-2: subclass 2 of class2; Group 2-2-1: Group 1 of subclass 2-2; Group 2-2-2:

Group 2 of subclass 2-2; Subgroup2-2-2-1: subgroup 1 of group 2-2-2; Subgroup2-2-2-2: subgroup2 of group2-2-2; E2-2-2-2-1: set 1 of subgroup2-2-2-2; E2-2-2-2-2: Group 2 of Subgroup 2-2-2-2.

\section{Discussion:-}

Morphometric measures on Callosobruchus maculatus show various values. Indeed, for most variables, the measures vary more or less according to a certain average. However, variables such as the minimum distance between the dorsal eyes (Lmf) and the number of teeth at the femur 3 (den) have constant values in all individuals sampled. These two variables therefore do not discriminate individuals from different populations. This corresponds to the work of Delobel (1993) which establishes the number of teeth as a non-discriminating parameter but rather as a characteristic variable of the species C. maculatus. Thus, on 15 chosen variables only 13 variables (Lan, Dvy, Lmt, Lop, Lap, Lf3, Lt3, Loe, Lae, Los, Las, Lds, lds) are used to obtain relevant information on the Morphometric variability of the species. 
For the raw measurements of these morphometric variables used, the best representation is obtained by the first two factorial axes 1 and 2. The latter account for $48.41 \%$ of the morphometric variability. According to these same factorial axes, a slight discrimination is observed between two groups: the individuals of VFS, HCSO and those of the SP zone, NBA and SBA. Indeed, the populations of these different agro-ecological zones do not appear to present at first great differences, due to the approximation of their clouds of points, which could suggest an important gene flow between the different populations. But a more detailed study of the representative barycenters of each population showed a slight discrimination. However, an apparent correlation of most variables is largely due to a common factor that can be assimilated as a first approximation to a size factor.

The reduction in the weight of this factor results in a slight decrease in overall discrimination between agroecological zones and a slight increase in the distance between the barycenters. Thus the transformed data results in a reduction of the percentage of inertia to $42.17 \%$, i.e a decrease of $6.13 \%$ of the total morphometric variability and offers a better redistribution of the variables with respect to their contribution to the axis. With the transformed data, along the factor axis 1, a slight discrimination is observed between the individuals of the agro-ecological zones HCSO, VFS, SBA and those of the NBA, SP. On the other hand, along the factorial axis 2, a slight differentiation is detected between the individuals of the agro-ecological zone SBA and those of the HCSO and the VFS. Considering the measure of each variable obtained after transformation, NBA individuals show the greatest dimensions for the following variables: length of the elytra $(1.93 \mathrm{~mm})$, length of the antenna $(2 \mathrm{~mm})$, length of the tibia $3(1.04 \mathrm{~mm})$, while the largest dimensions of the pronotum (length: $0.99 \mathrm{~mm}$, width: $1.23 \mathrm{~mm}$ ) and the maximal width of the head $(0.9 \mathrm{~mm})$ are observed in SP individuals. The SBA has a longer sternite length $(1.58 \mathrm{~mm})$ followed by HCSO $(1.54 \mathrm{~mm})$ and NBA $(1.53 \mathrm{~mm})$ ecotypes. The last sternite is longer in individuals of the HCSO $(1.27 \mathrm{~mm})$ and VFS (1.22 mm) ecotype.

The factorial correspondence analysis shows that of the five axes explaining all the morphometric variability, only the first three axes give a better insight into the discrimination between the ecotypes with $79,63 \%$. It mainly identifies 4 morphometric groups, including those already discriminated against with AFD, i.e the group of the groundnut basin, the grouping of individuals from HCSO, SP, NBA, and virtually only individuals with VFS. But there is also a distribution of some ecotypes to new groups such as NBA individuals that have affinities with those of HCSO and MS.

The ecotypes studied as a whole show a certain degree of similarity as shown by the assignment test. Indeed, all the ecotypes tested become composite, so some individuals belonging to a previously defined zone have more similarities with other individuals from neighboring agro-ecological zones: those of the NBA, $20 \%$ of which are reassigned to the SBA; But also with individuals of less close zone: case of the SBA of which $46.7 \%$ of the individuals are closer to those of VFS. The distance does not seem to correspond to a discriminatory criterion and therefore does not intervene in the variation of the morphology of the species nor the climatic conditions. Apart from this semblance of homogeneity, VFS is revealed to be the most homogeneous population (46.7\% correctly assigned) whereas the SBA is the most heterogeneous. The groundnut basin being an agricultural granary, one would think that this is a valid explanation for the highly heterogeneous nature of the individuals in this ecotype.

The results with hierarchical ascending classification, which globally identify 6 groups, do not isolate particular morphometric groups but show a certain discrimination of an individual particularly compared to the rest. Indeed the individual CmD14 seems to have characteristics that separate it from the set. Concerning the other individuals, the degree of similarity mentioned above remains with groups always composite on the origin of the individuals. However, more similarity between NBA and HCSO individuals is noted, but also between individuals in the SBA and those in MS that seem even closer.

\section{Conclusion:-}

The study of the morphometric characterization of Callosobruchus maculatus aims at verifying whether the spatial distribution of $C$. maculatus affects its morphology. It revealed morphometric groups more and less distinct especially between the sylvo-pastoral zone and the high Casamance in the Eastern Senegal. However, further studies are needed to understand what is causing the existence of these more or less distinct groups. A genetic study is also needed to see if the morphometric differences detected between groups are observable at the molecular level using mitochondrial genes that are genes with little variable. 
Bibliographical references:-

Belkhir K., Borsa P., Chikhi L.,

1. Raufaste N., and Bonhomme F. 2004.

GENETIX 4.05, logiciel sous Windows TM pour la génétique des populations. Laboratoire Génome, Populations, Interactions, CNRS UMR 5171, Université de Montpellier II, Montpellier (France). Disponible sur : " http://Kimura.univ-montp2.fr/genetix/constr.htm\#download ».

2. Bloomfield V.A. 2014. Using R for numerical Analysis in Science and Engineering. Chapman \& Hall/CRC The R Series, 359p (ISBN 978-14398844).

3. Delobel A. et Tran M. (1993). Les

Coléoptères des denrées alimentaires entreposées dans les régions chaudes. OSTROM / CTA, Faune tropicale XXXII. 312p

4. Hoda A., and Marsan P.A. 2012. Genetic

Characterization of Albanian Sheep Breeds by

Microsatellites Markers. Analysis of Genetic Variation in Animals, Prof. Mahmut Caliskan (ED.), ISBN:978-95351-0093-5, In Tech, Available from: «http://www.intechopen.com/books/analysis-of-genetic-variation-inanimals/genetic characterization-of-albanian-sheep-by microsatellite-markers».

5. Ngamo L. et Hanc TH., 2007. Diversité

des ravageurs des denrées et méthodes alternatives de lutte en milieu tropical, in Tropicultura, vol 25 ( $\left.{ }^{\circ} 4\right)$, 215220pp.

6. Kayombo et al, 2015. Effet de la poudre

de Tephrosia vogelii dans la conservation des graines de Niébé (VignaunguiculataL.Walp.) en stock contre Callosobruchus maculatus F. à Mbujimayi (RD. Congo)

7. Gueye et al, 2010. Lutte contre les

ravageurs des stocks de céréales et de légumineuses au Sénégal et en Afrique occidentale : synthèse bibliographique

8. FAO, 2011. Halte aux pertes post-récolte:

la sécurité alimentaire de l'Afrique est en jeu

9. Ilboudo, 2009. Activité Biologique de

quatre huiles essentielles contre Callosobruchus maculatus Fab. (Coleoptera : Bruchidae), insecte ravageur des stocks de niébé au Burkina Faso.

10. Santos F. (2015). Analyse en

Composantes Principales (ACP) : Travaux Pratiques avec le logiciel R. CNRS, UMR 5199 PACEA.

11. Seck, 1989. Les insectes ravageurs des

stocks de mais, mil et niébé en Afrique: importance économique et développement d'une approche de lutte intégrée.

12. Guèye MT., Dogo S., Wathel et

JP.,Lognay Georges (2011). Lutte contre les ravageurs des stocks de céréales et de légumineuses au Sénégal et en Afrique occidentale : synthèse bibliographique.Biotechnol. Agron. Soc. Environ. 2011 15(1), 183-194.

13. Sezonlin Michel (2006).

Phylogeographieetgenetique des populations du foreur de tiges de cerealesbusseolafusca (fuller) (lepidoptera, noctuidae) en afrique subsaharienne, implications pour la lutte biologique contre cet insect. Thèse de doctorat de l'université de Paris XI-Orsay. 152p. 